\title{
CUHSO
}

FACULTAD DE CIENCIAS SOCIALES 



\author{
res \\ REPRESENTANTE LEGAL \\ Dr. Aliro Bórquez Ramírez, Rector \\ DIRECTOR \\ Dr. José Manuel Zavala Cepeda \\ EDITORES ADJUNTOS \\ Dr. Ricardo Salas Astraín \\ Dr. Helder Binimelis Espinoza
}

COMITÉ CIENTÍFICO

Dr. Marcos Aguirre (Universidad Academia de Humanismo Cristiano, Chile)

Dr. Álvaro Bello (Universidad Católica de Temuco, Chile)

Dra. Alcira Bonilla (Universidad de Buenos Aires, Argentina)

Dr. Claudio Bolzmann (Escuela de Altos Estudios de Suiza Occidental, Suiza)

Dra. Magaly Cabrolié (Universidad Católica de Temuco, Chile)

Dr. Alfredo Carballeda (Universidad de Buenos Aires, Argentina)

Dra. Noelia Carrasco (Universidad de Concepción, Chile)

Dr. Raúl Fornet-Betancourt (Universidad de Bremen, Alemania)

Dr. Jorge Hidalgo (Universidad de Chile)

Dr. Fabien Le Bonniec (Universidad Católica de Temuco, Chile)

Dra. Francisca de la Maza (Pontificia Universidad Católica de Chile)

Dr. Lino Morán (Universidad de Zulia, Venezuela)

Dr. Alejandro Moreno (Universidad de Carabobo, Venezuela)

Dr. Carlos Pagano (Universidad Católica de Salta, Argentina)

Dr. Cristian Parker (Universidad de Santiago de Chile)

Dr. Jovino Pizzi (Universidad Federal de Pelotas, Brasil)

Dr. Enric Porqueres (Escuela de Altos Estudios de París, Francia)

Dr. Rodrigo Pulgar (Universidad de Concepción, Chile)

Dr. Pablo Salvat (Universidad Alberto Hurtado, Chile)

AYUDANTE EDITORIAL

María Inés Flores 


\section{CUHSO. CULTURA-HOMBRE-SOCIEDAD}

ISSN 07I6-I 557 | e-ISSN O7I6-2789| VOL. 22 | NRO. I | 3I DE JULIO DE 20 I2

La revista CUHSO es editada por la Facultad de Ciencias Sociales de la Universidad Católica de Temuco. Publica artículos inéditos en el campo de las ciencias sociales, en especial en líneas disciplinares como relaciones interétnicas, derechos humanos, desarrollo social y cultural, disciplina e interdisciplina y marginalidad urbana.

CUHSO cuenta con la asesoría y financiamiento de la Dirección General de Investigación y Posgrado en el marco de la estrategia de apoyo institucional a las publicaciones científicas de la Universidad Católica de Temuco, 20 I 2.

CUHSO es una publicación semestral y está indexada en Latindex.

COORDINADORA EDICIONES UNIVERSIDAD CATÓLICA DE TEMUCO

Andrea Rubilar Urra

Dirección General de Investigación y Posgrado

Avenida Alemania 02 I I, Temuco.

DISEÑO Y EDICIÓN

www.tipografica.cl

CuHSO. Cultura-Hombre-Sociedad

Casilla $15 \mathrm{D}$, Temuco.

Teléfono: $(56-45) 205233$

Email: cuhso@uctemuco.cl

CUHSO es distribuida bajo una Licencia

Creative Commons Atribución-NoComercial-SinDerivadas 3.0 Unported. 


\section{CUHSO. CULTURA-HOMBRE-SOCIEDAD}

ISSN O7I6-I 557 | e-ISSN O7I6-2789| VOL. 22 | NRO. I | 3 I DE JULIO DE 20 I2

\section{Contenidos}

Editorial .................................................................................... 7

GRACIELA ALCALÁ

Demografía, desarrollo y control del espacio litoral

en la costa del Pacífico mexicano I I

GONZALO SAAVEDRA GALLO

Pesca artesanal y salmonicultura en Aysén. Itinerario de una investigación crítica sobre el desarrollo en el sur austral de Chile

FRANCISCO THER RÍOS Y JAIME VALDERRAMA BRAVO

Dinámicas territoriales en asentamientos de pescadores artesanales: economías, experiencias y conflictos. El caso de Guabún y Puñihuil en la comuna de Ancud, Chiloé 6I

JOSÉ MILTON ANDRIGUETTO-FILHO Y NAÍNA PIERRI

Participación de pescadores artesanales en el diseño de un proyecto de implantación de arrecifes artificiales en el sur de Brasil 95

MARÍA EUGENIA SOLARI, JUAN CARLOS SKEWES, MAGDALENA NAVARRO Y FABIÁN PAILLACHEO

Historia ambiental de los archipiélagos de la Trapananda (Patagonia septentrional, Chile): desafíos para la conservación de la ballena azul I I 5

ANDRÉS MARÍN Y STEFAN GELCICH

Gobernanza y capital social en el comanejo de recursos bentónicos en Chile: aportes del análisis de redes al estudio de la pesca artesanal de pequeña escala I 3 I 
RESEÑA - CATALINA ÁlVAREZ BURGOS

Pescadores en América Latina y el Caribe I 55

RESEÑA - RICARDO SALAS

El valor de pensar I6I

Normas editoriales I 65 